\title{
La salud mental de los niños es lo primero
}

La Red Europea de Promoción de la Salud Mental y Salud Mental Europa han adoptado, en una reunión en Bruselas, el 27 de noviembre de 1999, una serie de recomendaciones para incrementar la conciencia de la importancia de la salud mental de los niños, y desarrollar políticas para promover la salud mental y el bienestar de los niños y sus familias.

La salud mental va mas allá de los trastornos mentales. La salud mental es un recurso esencial de la vida diaria y se moldea con las experiencias personales, individuales y colectivas. En las familias, escuelas, en las calles, etc. Existe una clara evidencia de que las experiencias en los primeros años de vida, tienen un impacto crucial sobre la salud mental de la vida adulta. El desarrollo de estrategias para promover la salud mental de los niños es de una importancia fundamental para el posterior desarrollo individual y social. La promoción de la salud mental es relevante para todo el mundo, sin distinción de edad, raza, religión, genero, estado de salud, habilidades o discapacidades. No hay salud sin salud mental.

Salud Mental Europa ha coordinado, durante dos años, un Proyecto de Promoción de la Salud Mental de niños menores de 6 años, financiado por la Comisión Europea. En el hemos colaborado 16 países, los miembros de la Comunidad Europea y Noruega, identificando 195 programas de promoción de la salud mental, realizados en diferentes contextos, en los que es necesario implementar medidas que aseguren el bienestar de los niños. A finales de enero del año 2000 , se publicara un directorio con todos los programas. Se puede encontrar también información en la pagina web: http://www.mhe-sme.org/enmhp.

Entre otras medidas, la Red Europea de Promoción de la Salud Mental recomienda adoptar las siguientes estrategias:

Una paternidad acogedora, responsable y sensible que facilite el desarrollo de las relaciones padres-niño.

Prestar una atención particular a los niños vulnerables (prematuros, niños discapacitados, niños víctimas de abusos o negligencias, niños de familias conflictivas, refugiados y con padres en paro).

Apoyar un entorno de seguridad, la amistad entre iguales, y un entorno no violento y acogedor.

Rev. Asoc. Esp. Neuropsiq., 2000, vol XX, n. ${ }^{\circ} 76$, pp. 107-108 
Desarrollar guarderías, escuelas y centros de día que enfoquen y promuevan la salud mental en la infancia.

La red también reconoce la necesidad de proporcionar fondos especiales para promover el desarrollo, implementaron y mantenimiento de iniciativas efectivas y eficaces económicamente, para promover la salud mental y el bienestar de los niños y las familias. Para mas información contactar con la Asociación Española de Neuropsiquiatría.

Asociación Española de Neuropsiquiatría 